\title{
Evidence for Inhibition of Exodus of Small Neutral Amino Acids from Non-brain Tissues in Hyperphenylalaninaemic Rats
}

\author{
C. de Cespedes, J. G. Thoene, K. Lowler and H. N. Christensen $\dagger$ \\ Departments of Biological Chemistry and Pediatrics, University of Michigan \\ Medical School, Ann Arbor, Michigan 48109, USA
}

\begin{abstract}
Summary: The mechanism of the depletion of several plasma amino acids in PKU has remained unexplained. In the present study, a statistically significant decrease in the plasma concentration of several amino acids was observed $2 \mathrm{~h}$ after the intraperitoneal injection of Phe to weanling rats. The pattern was very similar to the one observed in PKU patients. Statistically significant increases in the distribution ratios liver/plasma and, mainly, muscle/plasma ratios accompanied in most of the cases the corresponding decreases in plasma concentrations. Equimolar injection under the same conditions of the noninsulinogenic transport system $\mathrm{L}$ analogue, the $\mathrm{a}( \pm)$ isomer of the 2 -aminonorbornane-2-carboxylic acid, produced, in a parallel effect to Phe, statistically significant increases in the distribution ratios of Ala and Gly, and probably of Pro in muscle, as well as of Ala in liver. These results seem to indicate that the high intracellular Phe attained inhibits the exodus of small neutral amino acids through system $\mathrm{L}$, causing their depletion in plasma and ultimately in the brain. This effect may be additive to the inhibition by Phe of the entry of bulky neutral amino acids at the level of the blood-brain barrier. Further study is needed to assess the relevance of these effects to PKU.
\end{abstract}

The underlying pathogenetic mechanism that leads to mental retardation in phenylketonuria (PKU) is not known (Scriver and Clow, 1980). An inadequate supply of certain amino acids to the brain with the ensuing impairment of protein and/or neurotransmitter synthesis is likely to be a major factor contributing to the brain damage (Tourian and Sidbury, 1983).

In 1953, one of us (H.N.C.) predicted that the systemic accumulation of phenylalanine in PKU might interfere with the transport of several amino acids into the brain. This hypothesis has received strong support. Depletion of amino acids in the brain has been observed in animals with experimental hyperphenylalaninaemia (McKean et al., 1968) and at autopsy of PKU patients (McKean, 1972). Inhibition

TTo whom correspondence should be addressed

MS received 6.4.88 Accepted 29.11.88 
of influx of amino acids into the brain has been also observed in similar animal models (Partridge and Oldendorf, 1977), along with transport-competitive effects of phenylalanine in isolated human brain capillaries (Choi and Partridge, 1986). In general, the bulky neutral amino acids are mainly affected by Phe, a result that indicates that the inhibitory effect may occur at the level of transport system L in the blood-brain barrier (Wade and Katzman, 1975; Betz and Goldstein, 1978).

An accompanying paradox has received less attention. The plasma concentrations of several dipolar amino acids, the large ones less generally affected, decrease in plasma in PKU patients (Linneweh and Ehrlich, 1962; Efron et al., 1969). The mechanism of this change is not known; malnutrition and loss in the urine have been excluded as possible explanations; decreased intestinal absorption or loss into the gut lumen is unlikely (Efron et al., 1969).

Huether and colleagues (1984) have reported accumulation of several amino acids in various non-brain tissues of newborn rats chronically treated with phenylalanine and $\alpha$-MePhe. The mechanism of this accumulative effect has likewise not been explained.

It was observed some years ago in this laboratory that the muscle/plasma ratio (Christensen et al., 1948) or liver/plasma ratio (Christensen and Cullen, 1981) of some amino acids increase, rather than decrease, in the presence of certain system $\mathrm{L}$ substrates or analogues. The most likely explanation for this effect was taken to be an inhibitory action of the analogues on the exodus of the affected amino acids from tissues through system $L$. These observations have led Christensen to propose that the depletion of some plasma amino acids in PKU may be explained as a sequestering effect of Phe by a similar inhibition of the exodus of certain amino acids from non-brain tissues, causing their sequestration and possible accelerated catabolism (Christensen, 1986; 1987a, b). The aim of the present study was to test this hypothesis.

\section{EXPERIMENTAL PROCEDURES}

\section{Materials}

L-Phenylalanine was obtained from SIGMA. The racemic aminoexo isomer of the 2aminonorbornane-2-carboxylic acid, often designated as $\mathrm{a}( \pm) \mathrm{BCH}$, but abbreviated here as $\mathrm{aBCH}$, was our own preparation (Tager and Christensen, 1972). Aspartame was provided to us by the NutraSweet Company. All other reagents were of the best grade commercially available.

\section{Animals}

Twenty-two-day-old Sprague-Dawley male weanling rats, weighing $38-66 \mathrm{~g}$ were used for all the experiments. Rats were fasted for $20-24 \mathrm{~h}$ before each experiment.

\section{Procedure}

Phe or aBCH was injected intraperitoneally as an iso-osmotic solution at a dose of $10 \mathrm{mmol} / \mathrm{kg}$ body weight. Control rats received an intraperitoneal injection of 
$0.85 \% \mathrm{NaCl}$ in the corresponding volume. Aspartame was administered by stomach tube only partially dissolved as a slurry, $1.5 \mathrm{~g}$ per $\mathrm{kg}$, in $15 \mathrm{ml}$ water. Two hours after an administration, the rats were anaesthetized with ether. Blood was taken from the exposed heart and collected in a heparinized tube. Plasma was separated and deproteinized with an equal volume of $12 \%$ sulphosalicylic acid. Approximately $1 \mathrm{~g}$ of liver and $0.5 \mathrm{~g}$ of muscle from the left thigh were weighed and ground in a mortar with sand and a $10 \%$ solution of sulphosalicylic acid in a volume 4 times the fresh weight of the tissue in grams. The homogenate was filtered through Whatman \#1 paper. The protein-free filtrate was stored at $-20^{\circ} \mathrm{C}$ until analysis.

\section{Analysis}

Amino acids were measured with a 119 CL Beckman automatic amino acid analyser using a high-sensitivity amino acid standard solution from SIGMA.

\section{Calculations}

For calculation of apparent concentrations of amino acids in cell water, the liver and muscle samples were taken to contain, respectively, $49 \%$ and $62 \%$ intracellular and $22 \%$ and $15 \%$ extracellular water (Christensen and Cullen, 1981; Lowry and Hastings, 1942). The distribution ratio, tissue/plasma, was the ratio $\mu \mathrm{mol} \mathrm{kg}{ }^{-1}$ cell

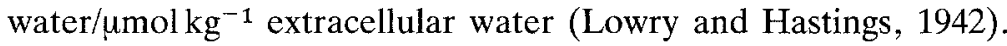

\section{Statistical analysis}

Differences in plasma levels, intracellular concentrations and distribution ratios between Phe- or aBCH-treated and control rats were calculated by the $t$ test using separate variances when the number of controls and treated animals differed (Wilkinson, 1986).

\section{RESULTS}

Plasma levels of Phe and tyrosine at various intervals after Phe injection are shown in Figure 1. Maximum levels of Phe, about 40 times the levels of the controls, were observed at $2 \mathrm{~h}$, although about $75 \%$ of the increase was seen by $30 \mathrm{~min}$. By $4 \mathrm{~h}$, a $75 \%$ decline from the peak was observed, and, by $8 \mathrm{~h}$, the levels had returned to control values. Presumably through the action of the uninhibited hepatic hydroxylase, Tyr increased, although at a slower rate than Phe, during the first $2 \mathrm{~h}$, increasing further as Phe decreased. On the basis of these results, all subsequent experiments were performed taking the samples at $2 \mathrm{~h}$ after injection.

Plasma amino acid levels and net intracellular concentrations in liver and muscle after Phe injection are shown in Table 1 . There was a statistically significant increase in the plasma concentrations of both Phe and Tyr; the ratio [Phe]/[Tyr] at $2 \mathrm{~h}$ was about 8/1. All other amino acids except $\mathrm{Glu}^{-}$showed decreased plasma levels $2 \mathrm{~h}$ after Phe administration, the difference being statistically significant for Leu, Ile, Ala, Pro, Gly, His, Orn and Arg. The valine decrease showed a $p$ value of 0.055 


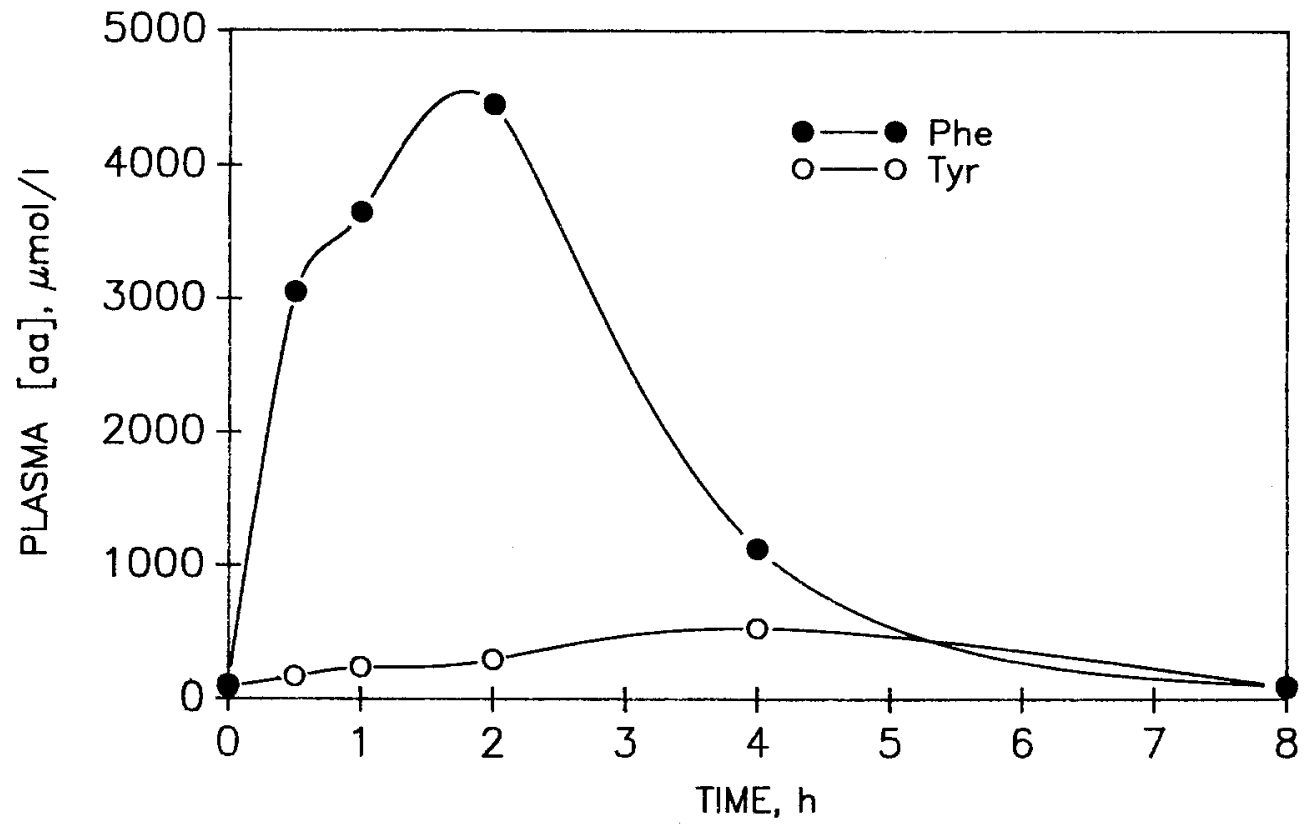

Figure 1 Time course of Phe and Tyr plasma levels after Phe administration. Each pair of points represents one animal. Values at 0 and $2 \mathrm{~h}$ in the same range of the means found in further experiments

Table 1 Plasma and net intracellular amino acid concentrations in controls and after Phe administration (for details see Experimental procedures). Values are means \pm S.D., $n=8$ controls, 8 experimental animals. Plasma and tissue levels are expressed in $\mu \mathrm{mol} / \mathrm{L}$ and $\mu \mathrm{mol} / \mathrm{kg}$ tissue, respectively

\begin{tabular}{|c|c|c|c|c|c|c|}
\hline & \multicolumn{2}{|c|}{ Plasma } & \multicolumn{2}{|c|}{ Liver } & \multicolumn{2}{|c|}{ Muscle } \\
\hline & Control & +Phe & Control & +Phe & Control & + Phe \\
\hline Phe & $104 \pm 28$ & $4421 \pm 868^{*}$ & $60 \pm 39$ & $1348 \pm 786^{* *}$ & $138 \pm 73$ & $3560 \pm 670^{*}$ \\
\hline Tyr & $93 \pm 23$ & $537 \pm 108^{*}$ & $39 \pm 21$ & $327 \pm 106^{*}$ & $124 \pm 47$ & $509 \pm 117^{*}$ \\
\hline Trp & $116 \pm 27$ & $103 \pm 34$ & $42 \pm 39$ & $56 \pm 32$ & $67 \pm 44$ & $94 \pm 83$ \\
\hline Leu & $254 \pm 27$ & $139 \pm 37^{*}$ & $151 \pm 89$ & $134 \pm 38$ & $228 \pm 91$ & $198 \pm 77$ \\
\hline Ileu & $175 \pm 37$ & $105 \pm 32 \dagger$ & $53 \pm 50$ & $61 \pm 28$ & $180 \pm 63$ & $141 \pm 61$ \\
\hline Val & $332 \pm 49$ & $268 \pm 71+\dagger$ & $209 \pm 128$ & $184 \pm 65$ & $285 \pm 106$ & $257 \pm 84$ \\
\hline Ala & $419 \pm 120$ & $219 \pm 128 \dagger$ & $1056 \pm 494$ & $1756 \pm 674^{* *}$ & $1897 \pm 1369$ & $2261 \pm 1481$ \\
\hline Pro & $188 \pm 38$ & $99 \pm 42 \dagger$ & $67 \pm 60$ & $77 \pm 37$ & $367 \pm 103$ & $644 \pm 318^{* *}$ \\
\hline Gly & $625 \pm 121$ & $391 \pm 134 \dagger$ & $2392 \pm 1127$ & $2381 \pm 680$ & $5287 \pm 3030$ & $6807 \pm 3921$ \\
\hline His & $83 \pm 20$ & $59 \pm 11 \dagger$ & $376 \pm 224$ & $377 \pm 137$ & $369 \pm 102$ & $428 \pm 94$ \\
\hline Orn & $82 \pm 23$ & $53 \pm 27^{* *}$ & $233 \pm 118$ & $193 \pm 66$ & $285 \pm 91$ & $316 \pm 134$ \\
\hline Arg & $167 \pm 26$ & $100 \pm 21^{*}$ & N.D. & N.D. & $1029 \pm 319$ & $1018 \pm 108$ \\
\hline Lys & $436 \pm 176$ & $317 \pm 146$ & $403 \pm 361$ & $439 \pm 181$ & $3166 \pm 1380$ & $2877 \pm 1587$ \\
\hline Gln & $608 \pm 195$ & $471 \pm 186$ & $1728 \pm 848$ & $1013 \pm 532$ & $3853 \pm 2792$ & $3642 \pm 2051$ \\
\hline Glu & $184 \pm 61$ & $226 \pm 195$ & $1592 \pm 1030$ & $1548 \pm 688$ & $2172 \pm 637$ & $2933 \pm 614^{* *}$ \\
\hline
\end{tabular}

${ }^{*} p<0.001 ; \dagger p<0.01 ;{ }^{* *} p=<0.05 ; \dagger \dagger p=0.055$; N.D. $=$ undetectable by the analysis used 
(Table 1). In general, the amino acid pattern in plasma was very similar to the one reported by Linneweh and Ehrlich (1962) and Efron and colleagues (1969) in PKU children (Figure 2).

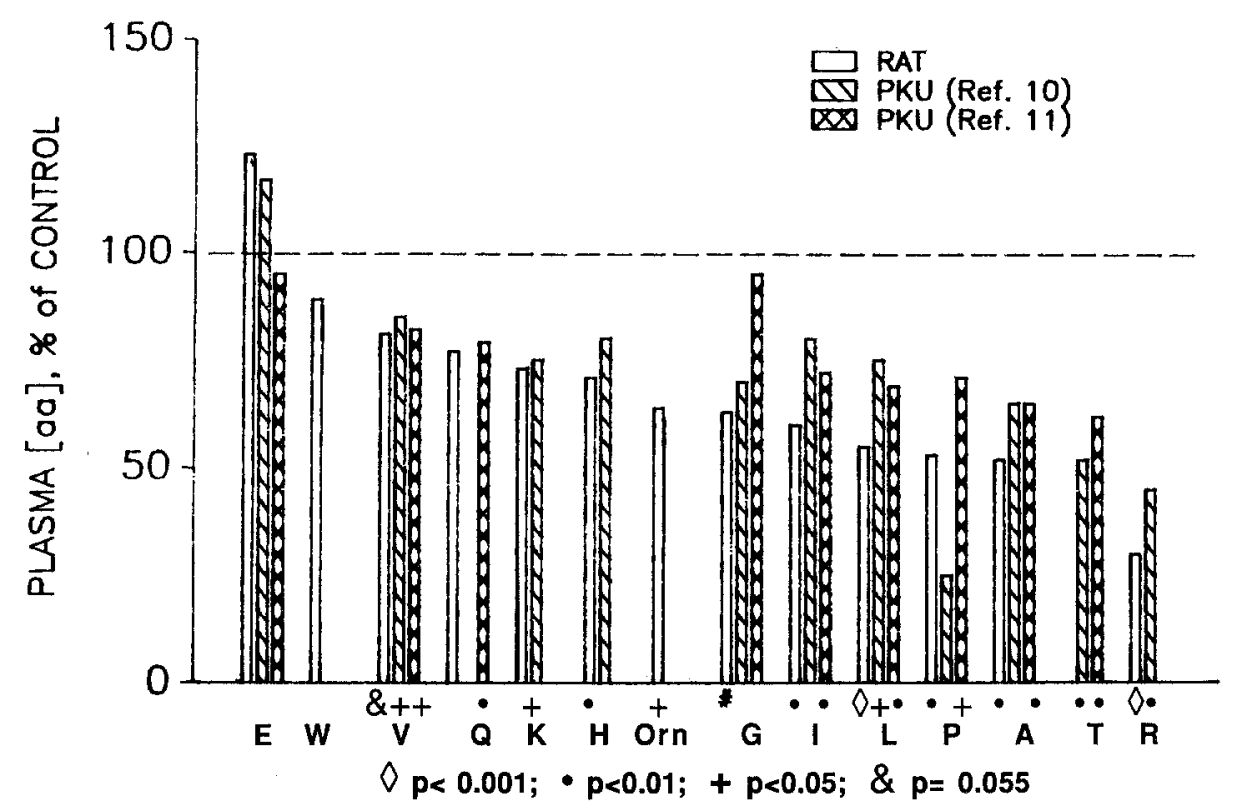

Figure 2 Plasma amino acid levels after Phe administration in rats and in PKU children off treatment. Plasma concentrations from Table 1 and from Linneweh and Ehrlich (1962) and Efron and colleagues (1969) are shown here as per cent of control. Non-essential amino acids were not included in the statistical calculations in Linneweh and Ehrlich. The oneletter abbreviations are Glu, E; Trp, W; Val, V; Gln, Q; Lys, K; His; H; Gly, G; Ileu, I; Leu, L; Pro; P; Ala, A; Thr, T; Arg, R

Statistically significant increases in net intracellular concentrations were found for Phe and Tyr in both organs studied (Table 1); the ratio [Phe]/[Tyr] reached at $2 \mathrm{~h}$ was $4 / 1$ and $7 / 1$ in liver and muscle, respectively. In liver, aside from Phe and Tyr, Ala was the only amino acid that showed a statistically significant increase in net intracellular concentration. In muscle, only Pro and $\mathrm{Glu}^{-}$showed statistically significant increases in their net intracellular concentrations (Table 1).

Amino acid distribution ratios, liver/plasma and muscle/plasma, after Phe injection are shown in Table 2. Owing to the extremely high plasma levels attained, hepatic Phe showed an almost statistically significant decrease in its distribution ratio in spite of the high intracellular concentration reached $(p=0.051)$. All other amino acids except $\mathrm{Glu}^{-}$showed an increase in their distribution ratio in liver, although the difference was statistically significant only for Ala, Gly and Lys (Table 2, column 3).

In muscle, both Phe and Tyr showed decreases in their distribution ratios after Phe injection, but the difference was statistically significant only for Tyr. All other amino acids showed increases in their distribution ratios; the difference was 
Table 2 Changes in relative concentrations and distribution of each of 15 amino acids produced after injecting $L$-Phe or aBCH into weanling rats

\begin{tabular}{|c|c|c|c|c|c|c|}
\hline & \multicolumn{3}{|c|}{ Phe injection } & \multicolumn{3}{|c|}{$a B C H$ injection } \\
\hline & Plasma & Liver & Muscle & Plasma & Liver & Muscle \\
\hline \multirow{2}{*}{$\begin{array}{l}\text { Phe } \\
\text { D.R. }\end{array}$} & \multirow[t]{2}{*}{$4300^{*}$} & $2250 \dagger$ & $2580^{*}$ & \multirow[t]{2}{*}{124} & 105 & 109 \\
\hline & & 0.50 & 0.62 & & 1.09 & 0.84 \\
\hline \multirow{2}{*}{$\begin{array}{l}\text { Tyr } \\
\text { D.R. }\end{array}$} & \multirow{2}{*}{$580^{*}$} & $840^{*}$ & $410^{*}$ & \multirow[t]{4}{*}{99} & 82 & 93 \\
\hline & & 1.41 & $0.72 \uparrow$ & & 1.18 & 1.03 \\
\hline \multirow{2}{*}{$\begin{array}{l}\text { Trp } \\
\text { D.R. }\end{array}$} & \multirow[t]{2}{*}{89} & 133 & 140 & & & \\
\hline & & 1.52 & 1.34 & & & \\
\hline \multirow{2}{*}{$\begin{array}{l}\text { Leu } \\
\text { D.R. }\end{array}$} & \multirow[t]{2}{*}{$55^{*}$} & 89 & 87 & \multirow[t]{2}{*}{121} & 84 & 93 \\
\hline & & 1.31 & $1.56 \dagger$ & & 1.06 & 0.88 \\
\hline \multirow{2}{*}{$\begin{array}{l}\text { Ileu } \\
\text { D.R. }\end{array}$} & \multirow[t]{2}{*}{$60^{* *}$} & 115 & 78 & \multirow[t]{2}{*}{108} & 68 & 89 \\
\hline & & 2.19 & 1.29 & & 1.03 & 0.84 \\
\hline \multirow{2}{*}{$\begin{array}{l}\text { Val } \\
\text { D.R. }\end{array}$} & \multirow[t]{2}{*}{81} & 88 & 90 & \multirow[t]{2}{*}{113} & 71 & 92 \\
\hline & & 1.24 & 1.25 & & 1.01 & 1.19 \\
\hline \multirow{2}{*}{$\begin{array}{l}\text { Ala } \\
\text { D.R. }\end{array}$} & \multirow[t]{2}{*}{$52 * *$} & $167 \dagger$ & 119 & \multirow[t]{2}{*}{91} & 92 & 101 \\
\hline & & $3.74^{* *}$ & $2 \cdot 62 \dagger$ & & $1.53 \uparrow \ddagger$ & $1.68 t$ \\
\hline \multirow{2}{*}{$\begin{array}{l}\text { Pro } \\
\text { D.R. }\end{array}$} & \multirow[t]{2}{*}{$53^{* *}$} & 115 & $175 \dagger$ & \multirow[t]{2}{*}{90} & 80 & 102 \\
\hline & & 2.19 & $3.93^{*}$ & & 0.56 & 1.32 \\
\hline \multirow{2}{*}{$\begin{array}{l}\text { Gly } \\
\text { D.R. }\end{array}$} & \multirow[t]{2}{*}{$63^{* *}$} & 100 & 129 & \multirow[t]{2}{*}{$71 \dagger$} & $70^{* *}$ & 107 \\
\hline & & $1.88+$ & $2.18 \dagger$ & & 1.05 & $1.80^{* *}$ \\
\hline \multirow{2}{*}{$\begin{array}{l}\text { His } \\
\text { D.R. }\end{array}$} & \multirow[t]{2}{*}{$71^{* *}$} & 100 & 116 & 126 & 85 & 87 \\
\hline & & 1.50 & $1.56+$ & & 0.84 & 0.76 \\
\hline Orn & $65 t$ & 83 & 111 & 94 & 77 & 79 \\
\hline D.R. & & 1.50 & $1.88^{* *}$ & & 1.07 & 0.98 \\
\hline Arg & $60 *$ & Not & 99 & 99 & Not & 120 \\
\hline D.R. & & detected & $1.98^{* *}$ & & detected & 1.20 \\
\hline Lys & 73 & 109 & 90 & 101 & 114 & 99 \\
\hline D.R. & & $1.87 \dagger$ & 1.30 & & 1.58 & 0.92 \\
\hline Gln & 77 & 58 & 95 & & & \\
\hline D.R. & & 1.10 & 1.34 & & & \\
\hline Glu & 124 & 97 & $135 \dagger$ & & & \\
\hline D.R. & & 1.03 & 1.62 & & & \\
\hline
\end{tabular}

The 3 values in each column parallel with the abbreviation (Column 1) of the amino acids show, for plasma, liver and muscle, respectively, the percentage of the control value attained in $2 \mathrm{~h}$ for each of these tissues. The number just below the percentage value for each amino acid shows the calculated relative distribution ratio (D.R.) between the concentrations in the cellular and extracellular water, as described under Methods, for the indicated solid tissue. The number of animals represented by each value varies from 7 to 13 , both for control and experimental groups. See Tables 1 and 3 for the analytically determined concentrations which served for calculating these amino acid distributions. The superscript symbols indicate the statistical significance of changes

${ }^{*} p<0.001,{ }^{* *} p<0.01, \dagger p<0.05, \dagger \dagger p<0.07$

statistically significant for Leu, Ala, Pro, Gly, His, Orn and Arg (Table 2, column 4).

Parallel experiments to those with Phe were made with aBCH (Table 2). This isomer of $\mathrm{BCH}$ was selected because it is not an insulin secretagogue (Tager and 
Christensen, 1971) and could serve to dissociate that action from the suspected direct effects on amino acid transport.

Gly showed a statistically significant decrease in both plasma and liver concen-

Table 3 Plasma and net intracellular amino acid concentrations in controls and after aBCH administration (for details see Experimental procedures). Values are means + S.D.; $n=5$ controls, 7 experimental animals. Plasma and tissue levels are expressed in $\mu \mathrm{mol} / \mathrm{L}$ and $\mu \mathrm{mol} / \mathrm{kg}$ tissue, respectively

\begin{tabular}{|c|c|c|c|c|c|c|}
\hline & \multicolumn{2}{|c|}{ Plasma } & \multicolumn{2}{|c|}{ Liver } & \multicolumn{2}{|c|}{ Muscle } \\
\hline & Control & $+a B C H$ & Control & $+a B C H$ & Control & $+a B C H$ \\
\hline Phe & $72 \pm 14$ & $89 \pm 22$ & $61 \pm 12$ & $64 \pm 12$ & $96 \pm 22$ & $102 \pm 22$ \\
\hline Tyr & $71 \pm 18$ & $70 \pm 21$ & $56 \pm 16$ & $46 \pm 10$ & $118 \pm 26$ & $106 \pm 21$ \\
\hline Leu & $224 \pm 65$ & $271 \pm 119$ & $265 \pm 84$ & $223 \pm 59$ & $249 \pm 94$ & $231 \pm 84$ \\
\hline Ileu & $309 \pm 274$ & $335 \pm 306$ & $142 \pm 86$ & $97 \pm 58$ & $220 \pm 145$ & $196 \pm 105$ \\
\hline Val & $206 \pm 44$ & $230 \pm 89$ & $258 \pm 61$ & $183 \pm 71$ & $250 \pm 59$ & $230 \pm 59$ \\
\hline Ala & $318 \pm 50$ & $289 \pm 93$ & $1605 \pm 555$ & $1470 \pm 445$ & $3107 \pm 961$ & $3145 \pm 715$ \\
\hline Pro & $156 \pm 28$ & $141 \pm 40$ & $146 \pm 103$ & $116 \pm 68$ & $378 \pm 123$ & $385 \pm 178$ \\
\hline Gly & $556 \pm 106$ & $393 \pm 108$ & $2882 \pm 43$ & $2019 \pm 535^{*}$ & $6755 \pm 1626$ & $7243 \pm 1646$ \\
\hline His & $65 \pm 26$ & $82 \pm 18$ & $510 \pm 79$ & $432 \pm 115$ & $394 \pm 109$ & $342 \pm 60$ \\
\hline Orn & $52 \pm 17$ & $49 \pm 17$ & $269 \pm 58$ & $202 \pm 36$ & $260 \pm 117$ & $206 \pm 68$ \\
\hline Arg & $138 \pm 16$ & $133 \pm 38$ & N.D. & N.D. & $684 \pm 242$ & $822 \pm 221$ \\
\hline Lys & $402 \pm 170$ & $405 \pm 145$ & $788 \pm 426$ & $895 \pm 431$ & $3162 \pm 1031$ & $3138 \pm 949$ \\
\hline
\end{tabular}

${ }^{*} p<0.01 ; t p<0.05 ;$ N.D. $=$ undetectable by the analysis used

trations after aBCH injection (Table 3). With the exception of Ala, Gly, Pro and Arg in muscle, there was a tendency of most amino acids to be decreased intracellularly after aBCH injection in both organs studied. In no case, however, were the changes statistically significant (Table 3 ).

Ala showed an increase in its liver/plasma distribution ratio after aBCH injection on the verge of statistical significance $(p=0.07)$. In no case were the changes in distribution ratios, if any, for other amino acids in liver statistically significant (Table 2, column 6).

Ala and Gly showed statistically significant increases in their muscle/plasma distribution ratios after the administration of aBCH. Pro, although the amino acid whose distribution ratio increased the most next to Ala and Gly (Figure 3, panel D), showed a $p$ value of 0.2 for the increase in its muscle/plasma distribution ratio. The combined distribution ratios, muscle/plasma of the three small neutral amino acids, showed, however, a statistically significant difference when considered collectively (Figure 3). Despite the considerable variance, we find the general downward trends impressive.

Aspartame administered by stomach tube as a $10 \%$ slurry in a dose of $1.5 \mathrm{~g}$ per $\mathrm{kg}$ body weight, approximately equivalent to the phenylalanine injected, led, in $2 \mathrm{~h}$ (4 animals), to increases of the plasma phenylalanine by about four-fold, to $0.2 \mathrm{mmol} / \mathrm{L}$, and of the tyrosine as a significant contrast by about ten-fold, to $0.5 \mathrm{mmol} / \mathrm{L}$. Several of the same amino acids lowered in the plasma by phenylalanine (e.g Gly, Pro, Met, Arg, Val) tended downward. Observations on one animal 


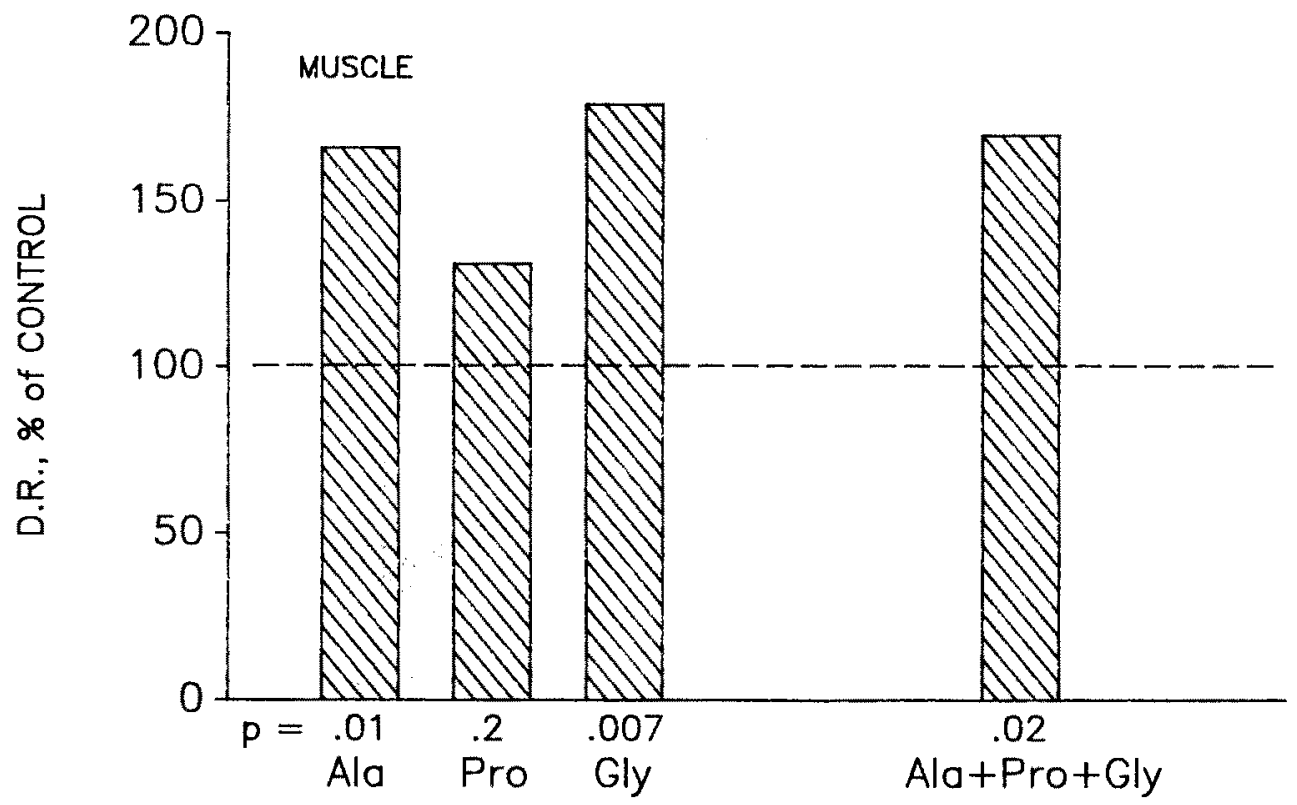

Figure 3 Distribution ratios muscle/plasma for the small neutral amino acids, Ala, Pro and Gly, after aBCH administration. Results are expressed as per cent of control; $n$ varied from 7 to 13 animals for both control and experimental observations

each at 1 and $1.5 \mathrm{~h}$ already indicated the same tendencies. Because of the complications of interpretation arising from possible effects of aspartate released from aspartame (e.g. distinct rises seen for plasma Ala and Gln), we did not, in this case, extend our results to the point of general statistical significance for the declines in plasma animo acid levels.

\section{DISCUSSION}

We lack an animal model to represent PKU and the usual experimental approach by inducing hyperphenylalaninaemic states in rats has important drawbacks. Phe administered chronically results in a higher concentration of Tyr in plasma, an effect opposite to the change observed in the human disease. Inhibitors of Phe hydroxylase, in particular p-ClPhe, are not entirely specific and show considerable toxicity manifested as loss of weight and high mortality (Vorhees et al., 1981). Therefore, we used no inhibitor of the hydroxylase in the present study. Under our experimental conditions, statistically significant increases in the concentration of Phe in plasma and tissues were nevertheless obtained. Although Tyr also increased significantly in plasma and tissues, the mean [Phe]/[Tyr] ratios were $8 / 1,4 / 1$, and $7 / 1$ in plasma, liver and muscle, respectively (Table 1). Moreover, the statistically significant decrease of the muscle/plasma ratio for Tyr (Table 2, column 4), consistent with the slower rise in plasma Tyr concentration than Phe (Figure 1), 
indicates that, at least in muscle, Tyr had not yet attained a steady-state distribution by the time our experiments were terminated. Therefore, we believe that the effects observed here were caused mainly by elevation of Phe and not of Tyr.

From previous work in this laboratory, we have learned that, under normal conditions, changes in amino acid concentrations in plasma and tissues tend to go in the same direction (Christensen et al., 1948). Only when selective inhibitors e.g. amino acid analogues, are present do changes in the distribution ratio tend to occur.

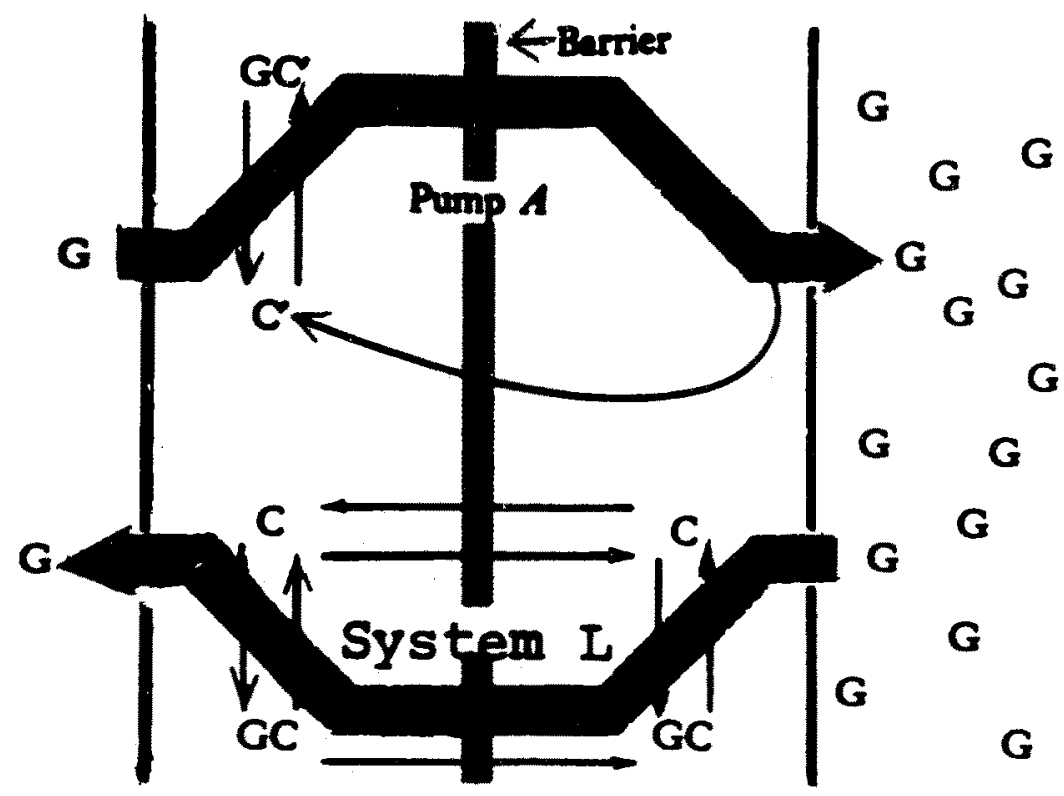

Figure 4 Diagram to illustrate the parallel operation of two transport systems in non-brain tissues. The $\mathrm{Na}^{+}$-dependent systems, such as $\mathrm{A}$, tend to be highly concentrative for $\mathrm{G}$, so that $\mathrm{Na}^{+}$-independent, system $\mathrm{L}$ is caused to serve mainly for its exodus. $\mathrm{G}$ may represent Gly, Ala or Pro in this study, but may represent any other system L substrate that is also concentrated by system $\mathrm{A}$, as is Phe itself. $\mathrm{BCH}$ is also transported by system $\mathrm{L}$. Either Phe or $\mathrm{BCH}$ inhibits the exodus of $\mathrm{G}$ through system $\mathrm{L}$.

These effects are illustrated in the diagram of Figure 4. The parallel operation of two transport systems is shown for an amino acid that is pumped into the cell by a strongly concentrative transport system, such as system A. System L, generally being weakly concentrative, is forced to operate for net exodus by the high amino acid concentration attained inside the cell through the action of the $\mathrm{Na}^{+}$-dependent systems (Christensen, 1986; 1987a; 1987b; Christensen and Handlogten, 1979). In fact, it has been observed in this laboratory that the usually specific system $\mathrm{A}$ inhibitor, 2-aminoisobutyric acid, or its more uniformly specific $N$-methyl derivative, causes decreases of the hepatic levels of amino acids relative to their plasma levels (Christensen and Cullen, 1968), whereas the relatively specific system L inhibitor, $\mathrm{BCH}$, causes corresponding increases (Christensen and Cullen, 1981). Phe, as well as other amino acids preferring system $L$ for passage, has been shown 
to increase the distribution ratio, tissue/plasma, for Gly in the liver and in the thigh muscle of the guinea pig (Christensen et al., 1948).

At the level of the blood-brain barrier, however, system L was long the only transport system clearly recognized to function for neutral amino acids, the inward operation of system $\mathrm{A}$ at this site being apparently negligible (Wade and Katzman, 1975; Betz and Goldstein, 1978). Therefore, Phe or similar system L substrates will, we hold, tend to decrease the brain/plasma distribution ratio of a number of amino acids by transport competition.

In the present study, in all cases except that of Lys in liver, a statistically significant increase in distribution ratio after Phe injection was always accompanied by a statistically significant decrease in the plasma concentration of the corresponding amino acid (Table 2). Ala and Pro in liver and muscle, respectively, were the only two cases where an increase in net intracellular concentration accompanied their respective opposite changes in both plasma levels and distribution ratios. Only $\mathrm{Glu}^{-}$in muscle showed a statistically significant increase in the intracellular concentration without any other significant change (Table 2, column 4).

The effect of Phe in increasing the distribution ratios of Ala and Gly in liver and also those of Ala, Gly and Pro in muscle (Table 2, column 4) is produced also by the system $\mathrm{L}$ analogue, $\mathrm{aBCH}$, for $\mathrm{Ala}$ and Gly and probably also for Pro in muscle (Table 2, column 7; Figure 3) as well as for Ala in liver (Table 2, column 6). We think that these results can be explained by the mechanism discussed above. Ala, Gly and Pro, as preferred substrates of system A, are accumulated into the cells by this route and then the elevated intracellular Phe (Table 1) inhibits their exodus through system $\mathrm{L}$. In a parallel effect to the one observed for Phe, $\mathrm{aBCH}$ caused a statistically significant decrease in the plasma concentration of Gly accompanying the increase in the distribution ratio of this amino acid in muscle. Although the decreases in the plasma concentrations of Ala and Pro after the administration of $\mathrm{aBCH}$ failed to show statistical significance, on the basis of their increased tissue/ plasma ratios attained, we think that this trapping effect is a likely contributory mechanism for the decrease of these two amino acids in plasma in hyperphenylalaninaemia. It appears to be a major mechanism for the decrease in the plasma concentration of Gly under that condition. Previous results in this laboratory when Phe was fed to weanling rats at $5 \%$ in the diet for 6 days support the same conclusion (Christensen, 1987b).

The statistically significant decrease in the net intracellular concentration of Gly in liver after aBCH injection can best be explained by its rapid catabolism through increased mass action arising from strong inhibition of exodus. A similar effect may explain the lack of increase in net intracellular concentrations of other affected amino acids.

We have no compelling explanation at this time for the statistically significant increases by Phe of the distribution ratios in muscle of other amino acids, namely Leu and His and the cationic amino acids, Orn and Arg, all of which also showed a statistically significant decrease in plasma. The apparent parallelism in the effects of Phe and aBCH on Lys in liver (Table 2, columns 3 and 6) and Arg in muscle (Table 2, Columns 4 and 7) deserves, however, further study (see Oldendorf $e t a l$., 1988). 
It is not clear why the unexplained accumulations of various amino acids in nonbrain tissues of newborn rats treated with Phe and $\alpha$-MePhe observed by Huether and colleagues (1984) are seen only in the first perinatal days. These authors propose that the consequent depletion in plasma is the main factor contributing to the unavailability of amino acids to the brain and speculate that no competitive transport effects of Phe occur either at the blood-brain barrier (Huether et al., 1984) or elsewhere (Huether, 1987). We think that a direct effect of Phe on the blood-brain barrier need not be excluded in proposing a separate likely contributory effect of the sequestration in other tissues on the depletion of amino acids in the brain in hyperphenylalaninaemic states. Neither does an increased utilization of certain amino acids exclude transport effects of the kind we are describing here for muscle and liver. Moreover, these transport effects may prove to be the first step that leads to an increased utilization of the trapped amino acid by mass action, as is probably the case for Gly in liver as illustrated in this study (Table 2, columns 3 and 6).

We propose instead that Phe causes a depletion of neutral amino acids in the brain by means of a dual competitive effect, one affecting directly the entry especially of bulky neutral amino acids at the level of the blood-brain barrier, and another, according to the results in this study, inhibiting the exodus of small neutral amino acids from non-brain tissues.

Transport mechanisms in non-brain tissues have been proposed but not experimentally tested to explain the decrease in the plasma concentrations of isoleucine and valine after oral (Nyhan et al., 1961) and intravenous (Erikson et al., 1981) loads of leucine in humans. On the specific question faced here, Efron and colleagues (1969), on the basis of the already known inhibitory effect of Phe on the entry of some amino acids into the brain, excluded transport effects as an explanation for the decrease of plasma amino acids in PKU. It was not fully understood at that time, however, that a specific transport system tends to be given directionality in its operation by the flows of metabolism in various tissues.

Insulin concentrations in plasma have been found to be increased in PKU patients after a glucose load (Antonozzi et al., 1987). In fact, Phe is an effective insulin secretagogue in man (Fajans et al., 1967), although it appears be a very weak one in the rat, according to studies in the perfused pancreas (Landgraff et al., 1974) and also according to preliminary observations in our laboratory. In the present study, we purposely used a non-insulinogenic species of $\mathrm{BCH}$, the $\mathrm{a}( \pm)$ isomer (Tager and Christensen, 1971). Hence, the effect of Phe on the small neutral amino acids observed here seems to be related mainly to direct transport competitive effects. System A proves, however, a selective target of insulin in stimulation of amino acid transport in isolated preparations of rat liver and muscle (Shotwell et al., 1983). Even if secreted to a slightly increased extent in the pretreated rat, insulin could play a role to enhance the trapping effect by some administered amino acids described above. In man, the plasma levels of the branched-chain amino acids fell most during regulated insulin administration, although Pro and Ile were the most sensitive to insulin dose (Fukagawa et al., 1986). We are currently exploring possible contributory effects of insulin in the changes of plasma and tissue amino 
acids observed here, as well as after administration of Leu, the latter a clear insulin secretagogue in the rat (Landgraff et al., 1974).

It is apparent in this study that the small neutral amino acids are the most generally affected. Experimental studies by others have also shown significant changes in several small neutral amino acids after Phe treatment. Ala has been found to be the most severely depleted of the non-essential amino acids in the brain of hyperphenylalaninaemic 10-day-old rats (Lowden and LaRamee, 1969), although the occasionally overlooked brain metabolism of branched chain amino acids also received appropriate emphasis in these results. Gly uptake into rat liver and brain has been found to be stimulated by Phe in short-term experiments (ZanicGrubisic and Lipovac, 1981). The relationship of these effects to our findings is, however, not clear at this time.

Ala, Gly and Pro are non-essential according to the classical meaning of this term. The possibility that the brain may need to receive non-essential amino acids supplied by other tissues must, however, not be overlooked. This point brings us to the subject of interorgan nutrition (Christensen, 1987b;1982). For example, in discussing the availability of neurotransmitters in PKU, it is natural to think first only of Trp and Tyr. It is not known, however, if a shortage in the supply of blood Gly may also affect the concentration and further function of this neurotransmitter in the brain (Sershen et al., 1987). The exaggerated classical concept of essentiality of amino acids was so ingrained at the time of the publication of Linneweh and Ehrlich's paper that the non-essential amino acids were excluded from the calculations (1962 Figure 2).

The significance of the present results to an understanding of the pathogenesis of the brain damage in PKU has to be assessed by further work. We are currently looking for changes in amino acid distribution in rats treated chronically with Phe and $\alpha$-MePhe. A better animal model of PKU would, however, still be highly desirable. Complete plasma amino acid analysis in PKU patients at some times during treatment and at different metabolic states may also be enlightening to explain the significance of changes in other amino acids aside from Phe and Tyr in PKU.

It may be relevant that under our relatively acute experimental as well as more prolonged (Christensen, 1987b) conditions, we have observed a pattern of plasma amino acids very similar to the one reported in PKU children (Figure 2; Linneweh and Ehrlich, 1962; Efron et al., 1969). As far as we are aware, the plasma amino acid pattern characteristic of PKU had not previously been reproduced in animals (Dolan and Golin, 1967; Kaufman, 1977). It may also be relevant that Efron and colleagues (1969) found an enhanced decrease of the amino acids affected in plasma in two of their PKU patients after an intravenous infusion of Phe. The differences were, however, also statistically significant when the patients were in their chronic condition, as was also apparently the case in the patients of Linneweh and Ehrlich (1962). On the other hand, Snyderman and colleagues (1981), in measuring several amino acids in fasting newborn PKU patients, found that only Thr showed a statistically significant decrease in the plasma, although Ala and also Arg were decreased along with Thr in the cerebrospinal fluid. Age of the patients and length 
of fasting before sampling may be likely causes for the discrepancy between the different groups of PKU patients. Unfortunately, Thr always co-eluted with Ser in our analyses.

Small neutral amino acids are also, in general, prominently depleted in plasma in PKU (Figure 2). Ala, Pro and Gly were found to be sharply decreased in the Linneweh and Ehrlich study, but, as noted above, the significance of the changes was not assessed statistically. On the other hand, Ala and Pro were found to be significantly decreased in plasma in the study of Efron and colleagues; Gly showed a $p$ value of 0.05 as well as an additional decrease after Phe infusion (Efron $e t$ al., 1969). Moreover, Ala together with Gln and Asn have been considered to be the only 'non-essential' amino acids whose depressed concentrations in plasma are corrected during the usual dietary treatment of PKU (Perry et al., 1970). In the present study, Gln, once considered an importantly depleted amino acid in PKU (Perry et al, , 1970), was found to be decreased in plasma, although not to a statistically significant level $(p=0.17)$ (Table 1$)$. Although significantly decreased in plasma in PKU patients, Gln was one of the less effected amino acids in the study of Efron and colleagues (1969). Under our experimental conditions, we did not find statistically significant changes either in the distribution ratio or in the intracellular concentration of GIn in both liver and muscle (Tables 1 and 2).

Perturbed transport processes are likely to be a prime cause of the deleterious imbalances in PKU and related inborn errors of amino acid metabolism. The identification of the transport mechanisms involved may be relevant to the possibility of specific interventions through the administration of selected amino acids or even relatively inert amino acid analogues. Such a step might help to correct the imbalances and may also have the additional benefit of allowing a less stringent and more palatable diet. Although this approach has been proposed by other investigators (Brunner et al., 1979; Pratt, 1980), the focus previously has been directed exclusively to the brain and to the classical essential amino acids. We urge that, under our working hypothesis, other tissues and the amino acids usually considered as non-essential receive attention.

\section{ACKNOWLEDGEMENTS}

Support acknowledged from Grants DK33281 and DK25548 from the National Institutes of Health, United States Public Health Service. Dr de Cespedes has been working at the University of Michigan under a Fulbright Fellowship.

\section{REFERENCES}

Antonozzi, I., Carducci, C., Vestri, L., Manzari, V. and Dominici, R. Plasma amino acid values and pancreatic $\beta$-cell function in phenylketonuria. J. Inher. Metab. Dis. 10 (1987) $66-72$

Betz, A. L. and Goldstein, G. W. Polarity of the blood brain barrier. Neutral amino acid transport into isolated brain capillaries. Science 202 (1978) 225-227

Brunner, R. L., Vorhees, C. V., McLean, M. S., Butcher, R. E. and Berry, H. K. Beneficial 
effects of isoleucine on fetal brain development in induced phenylketonuria. Brain Res. 154 (1978) 191-195

Choi, T. B. and Partridge, W. M. Phenylalanine transport at the human blood brain barrier. Studies with isolated brain capillaries. J. Biol. Chem. 261 (1986) 6536-6541

Christensen, H. N. Metabolism of amino acids and proteins. Ann. Rev. Biochem. 22 (1953) 233-260

Christensen, H. N. Interorgan amino acid nutrition. Physiol. Rev. 62 (1982) 1193-1233

Christensen, H. N. Where, do the depleted plasma amino acids go in phenylketonuria? Biochem. J. 233 (1986) 929-930

Christensen, H. N. Hypothesis: Where the depleted plasma amino acids go in phenylketonuria, and why. Perspect. Biol. Med. 30 (1987a) 186-196

Christensen, H. N. Role of membrane transport in interorgan amino acid flows: Where do the depleted amino acids go in phenylketonuria? In Kaufman, S. (ed.) Amino Acids in Health and Disease: New Perspectives, Alan R. Liss, Inc., New York, 1987b, Vol. 55, pp. $1-16$

Christensen, H. N. and Cullen, A. M. Effects of non-metabolizable analogs on the distribution of amino acids in the rat. Biochim. Biophys. Acta 150 (1968) 237-252

Christensen, H. N. and Cullen, A. M. Intensified gradients for endogenous amino acid substrates for transport system $L$ on injecting a specific competitor for that system. Life Sci. 29 (1981) 749-753

Christensen, H. N. and Handlogten, M. E. Interaction between parallel transport systems examined with tryptophan and related amino acids. J. Neural. Transm. Suppl. 15 (1979) $1-13$

Christensen, H. N., Streicher, J. A. and Elbinger, R. L. Effects of feeding individual amino acids upon the distribution of other amino acids between cells and extracellular fluid. $J$. Biol. Chem. 172 (1948) 515-524

Dolan, G. and Golin, C. Phenylketonuria in rats: a model for biochemical studies. Nature (London) 4 (1967) 916-917

Efron, M. L., Song Kong, E., Visakorpi, J. and Feller, F. X. Effects of elevated plasma phenylalanine levels on other amino acids in phenylketonuric and normal subjects. $J$. Pediatr. 74 (1969) 399-405

Erikson, S., Hagenfeldt, L. and Wahren, J. A comparison of the effects of intravenous infusion of individual branched chain amino acids on blood amino acid levels in man. Clin. Sci. 60 (1981) 95-100

Fajans, S. S., Floyd, J. S. Jr., Knopf, R. F. and Conn, J. W. Effects of amino acids and proteins on insulin secretion in man. Recent Progr. Horm. Res. 23 (1967) 617-662

Fukagawa, N. K., Minaker, K. L., Young, V. R. and Rowe, J. W. Insulin dose-dependent reductions in plasma amino acids in man. Am. J. Physiol. 250 (1986) E13-E17

Huether, G., Schott, K., Sprotte, U., Thoemke, F. and Neuhoff, V. Regulation of the amino acid availability in the developing brain. No physiological significance of amino acid competition in experimental hyperphenylalaninemia. Int. J. Dev. Neurosci. 2 (1984) 43-54

Huether, G. Regulation of the free amino acid pool in the brain: a lesson learned from experimental phenylketonuria. In Kaufman, S. (ed.) Amino Acids in Health and Disease: New Perspectives, Alan R. Liss, Inc., New York, 1987, Vol. 55, pp. 107-122

Kaufman, S. Phenylketonuria: Biochemical mechanisms. In Agranoff, B. W. and Aprison, M. H. (eds.), Adv. Neurochem., Vol. 2, Plenum Press, New York, 1977, pp. 1-132

Landgraff, R., Landgraf-Leurs, M. M. C. and Hörl, R. L-Leucine and L-phenylalanine induced insulin release and the influence of D-glucose. Kinetic studies with the perfused rat pancreas. Diabetologia 10 (1974) 415-420

Linneweh, F. and Ehrlich, M. Zur pathogenese des schwachsinns bei phenylketonuria. Klin. Wochenschr. 40 (1962) 225-226

Lowden, J. A. and LaRamee, M. A. Hyperphenylalaninemia: the effect on cerebral amino acid levels during development. Can. J. Biochem. 47 (1969) 883-888 
Lowry, O. H. and Hastings, A. B. Histochemical changes associated with aging. I. Methods and calculations. J. Biol. Chem. 143 (1942) 257-269

McKean, C. M. The effect of high phenylalanine concentrations on serotonin and catecholamine metabolism in the human brain. Brain Res. 47 (1972) 469-476

McKean, C. M., Boggs, D. E. and Peterson, N. A. The influence of high phenylalanine and tyrosine on the concentration of essential amino acids in brain. J. Neurochem. 15 (1968) $235-241$

Nyhan, W. L., Borden, M. and Childs, B. Idiopathic hyperglycinemia. A new disorder of amino acid metabolism. II. The concentration of other amino acids in plasma and their modification by the administration of leucine. Pediatrics 27 (1961) 539-545

Oldendorf, W. H., Crane, P. D., Braun, L. D., Gosschalk, E. A. and Diamond, J. M. pH Dependence of histidine affinity for blood-brain barrier transport systems for neutral and cationic amino acids. J. Neurochem. 50 (1988) 857-862

Partridge, W. M. and Oldendorf, W. H. Transport of metabolic substrates through the blood brain barrier. J. Neurochem. 28 (1977) 5-12

Perry, T. L., Hansen, S., Tischler, B., Bunting, R. and Diamond, S. Glutamine depletion in phenylketonuria: possible cause of mental defect. N. Engl. J. Med. 282 (1970) 761766

Pratt, O. E. A new approach to the treatment of phenylketonuria. $J$. Ment. Def. Res. 24 (1980) 203-217

Scriver, C. R. and Clow, C. L. Phenylketonuria: Epitome of human biochemical genetics. N. Engl. J. Med. 303 (1980) 1336-1342

Sershen, H., Debler, E. A. and Lajtha, A. Alteration of cerebral amino acid transport processes. In Kaufman, S. (ed.) Amino Acids in Health and Disease: New Perspectives, Alan R. Liss, Inc., New York, Vol. 55, 1987, pp. 87-104

Shotwell, M. A., Kilberg, M. S. and Oxender, D. L. The regulation of neutral amino acid transport in mammalian cells. Biochim. Biophys. Acta 737 (1983) 267-284

Snyderman, S. E., Sansaricq, C., Norton, P. M. and Castro, J. V. Plasma and cerebrospinal fluid amino acid concentrations in phenylketonuria during the newborn period. J. Pediatr. 99 (1981) 63-67

Tager, H. S. and Christensen, H. N. Hypoglycemic action of 2-aminonorbornane-2-carboxylic acid in the rat. Biochem. Biophys. Res. Commun. 44 (1971) 185-191

Tager, H. S. and Christensen, H. N. 2-Aminonorbornane-2-carboxylic acid. Preparation, properties and identification of the four isomers. J. Am. Chem. Soc. 94 (1972) 968-972

Tourian, A. and Sidbury, J. B. Phenylketonuria and hyperphenylalaninemia. In Stanbury, J. B., Wyngaarden, J. B., Fredrickson, D. S., Goldstein, J. L. and Brown, M. S. (eds.) The Metabolic Basis of Inherited Disease. 5th edn., McGraw Hill, New York, 1983, pp. 270-286

Voorhees, C. V., Butcher, R. E. and Berry, H. K. Progress in experimental phenylketonuria: a critical review. Neurosci. Biobehav. Rev. 5 (1981) 117-190

Wade, L. A. and Katzman, R. Synthetic amino acids and the nature of L-dopa transport at the blood brain barrier. $J$. Neurochem. 25 (1975) 837-842

Wilkinson, L. SYSTAT: The system for statistics. SYSTAT, inc., Evanston, IL, 1986

Zanic-Grubisic, T. and Lipovac, K. Disturbances of amino acid transport in rats with experimental hyperphenylalaninemia. J. Inher. Metab. Dis. 4 (1981) 105-106 